\title{
Association between type 2 diabetes mellitus and hypothyroidism: a case-control study
}

This article was published in the following Dove Press journal: International Journal of General Medicine

\author{
Anas Awad Alsolami' \\ Khalid Z Alshali' \\ Marwan Ahmad Albeshri' \\ Shikih Hussain Alhassan' \\ Abdalrhman Mohammed \\ Qazli' \\ Ahmed Saad Almalki' \\ Marwan A Bakarman² \\ Abdel Moniem Mukhtar' \\ 'Faculty of Medicine, Department of \\ Family and Community Medicine, King \\ Abdulaziz University, Jeddah, Saudi \\ Arabia; ${ }^{2}$ Department of Family and \\ Community Medicine, Rabigh Faculty \\ of Medicine, King Abdulaziz University, \\ Jeddah, Saudi Arabia
}

Correspondence: Anas Awad Alsolami Faculty of Medicine, Department of Family and Community Medicine, King Abdulaziz University, Prince Majid Rd, Al Sulaymaniyah, Jeddah 22252, Saudi Arabia Tel +966568781908

Email Solami.Anas@gmail.com
Objectives: Type 2 diabetes mellitus (DM-II) is highly prevalent in Saudi Arabia and only few studies have assessed it as a risk factor for hypothyroidism. This study aimed to examine the association between DM-II and hypothyroidism.

Subjects and methods: We conducted a hospital-based case-control study. As cases, we included all adults admitted to King Abdulaziz University Hospital (KAUH) with laboratoryconfirmed hypothyroidism. As controls, we drew a random sample of patients admitted to the orthopedic clinic at KAUH with laboratory-confirmed absence of hypothyroidism. We extracted data from the medical records regarding age, sex, presence of DM-II, HbA1c, comorbidities, treatment, and complications. We used multivariate logistic regression to identify factors associated with hypothyroidism.

Results: We included 121 cases and 121 controls. In comparison to controls, cases were older ( $P=0.005)$, had higher prevalence of DM-II $(P<0.001)$, had higher levels of HbA1c $(P=0.03)$, used insulin $(P<0.001)$ and oral hypoglycemic drugs $(P<0.001)$ more often, and suffered more often from hypertension $(P<0.001)$, coronary artery disease (CAD) $(P<0.001)$, stroke $(P=0.04)$, diabetic foot $(P<0.001)$, and nephropathy $(P<0.001)$. According to multivariate regression, the risk of hypothyroidism was significantly increased among patients with DM-II $(\mathrm{OR}=4.14 ; 95 \%$ $\mathrm{CI}=20.20-7.80 ; P<0.001)$ and $\mathrm{CAD}(\mathrm{OR}=14.15 ; 95 \% \mathrm{CI}=1.80-111.43 ; P=0.01)$.

Conclusion: Patients with DM-II were at increased risk of developing hypothyroidism. Adequate management and control of DM-II might reduce the risk of developing hypothyroidism. Further research using a prospective cohort study design is needed to confirm these findings.

Key messages: Patients with DM-II had an increased risk of developing hypothyroidism. Keywords: hypothyroidism, diabetes mellitus, comorbidities, complications

\section{Introduction}

Diabetes mellitus (DM) is one of the most common chronic diseases in the world, affecting 439 million adults, and its global prevalence is predicted to be $7.7 \%$ by 2030. ${ }^{1}$ Saudi Arabia has one of the highest rates of diabetes globally, with an estimated 3.4 million cases in 2015. The prevalence of DM in Saudi Arabia reached 30\%, with increasing incidence rates of both type 1 and type 2 DM (DM-II)., ${ }^{2,3}$

Long-term complications and organ damage caused by DM-II include retinopathy, nephropathy, neuropathy, and coronary artery disease (CAD). DM-II also has serious acute complications, which include hypoglycemic coma and diabetic ketoacidosis, and this imposes a high burden on the country's health care system and the economy. ${ }^{4-6}$

Recent literature showed some evidence of an association between DM-II and the risk of developing thyroid dysfunctions such as hypothyroidism, autoimmune hypo- 
thyroidism, and subclinical hypothyroidism. ${ }^{7-10}$ Accordingly, primary and subclinical hypothyroidism have been associated with DM-II. ${ }^{7-10}$ A study conducted by Diez et al in Spain found that the overall prevalence of thyroid dysfunctions in DM-II patients was $32.4 \%$. Another study conducted in Jordan showed that the prevalence of thyroid dysfunctions among DM-II patients was $12.5 \%$, whereas a recent study in India found that this prevalence was 31.2\%. ${ }^{11-13}$ However, these studies did not have a control group.

In spite of the high prevalence of DM-II in Saudi Arabia, the association between DM and thyroid dysfunctions has not been adequately studied. The aim of this study was to investigate whether DM-II increases the risk of developing hypothyroidism in Saudi Arabia.

\section{Subjects and methods}

We followed the STrengthening the Reporting of OBservational studies in Epidemiology (STROBE) guidelines for reporting our study methods and results. ${ }^{25}$

\section{Design}

We conducted a hospital-based case-control study in the Department of Medicine at King Abdulaziz University Hospital (KAUH) in Jeddah, Saudi Arabia, using electronic and paper-based patient records.

\section{Participants}

Cases were defined as patients $\geq 18$ years old who were admitted to KAUH between January 2000 and February 2016, had hypothyroidism as a discharge diagnosis, and had laboratory results of thyroid-stimulating hormone (TSH), free triiodothyronine (T3), and free thyroxine (T4) indicative of hypothyroidism. All patients who fulfilled these criteria were included as cases in the study. A similar number of controls were randomly selected from patients $\geq 18$ years old who were admitted to the orthopedic clinic of KAUH between January 2000 and February 2016, did not have hypothyroidism as an admission or discharge diagnosis, and had normal values of $\mathrm{TSH}$, free T3, and free T4.

\section{Variables and data measurements}

Using a standardized and pretested data extraction form, we collected data from the electronic hospital records of cases and controls. Then, we cross-validated these data against those found in the paper-based patient files. We extracted data on age, sex, hypothyroidism, DM-II, HbA1c, insulin, oral hypoglycemic agents, diabetic foot, retinopathy, nephropathy, hypertension, CAD, and stroke. We used the laboratory results of TSH, free T3, and free T4 to validate the presence and absence of hypothyroidism diagnosis. In order to validate our primary exposure variable, the diagnosis of DM-II, we used laboratory data on serum glucose level. We classified our patients as having diabetes or not according to the Saudi guidelines for management of diabetes. ${ }^{14}$ Patients with fasting plasma glucose of $\geq 7.0 \mathrm{mmol} / \mathrm{L}, 2$-hour plasma glucose of $11.1 \mathrm{mmol} / \mathrm{L}$ during an oral glucose tolerance test, random plasma glucose of $\geq 11.1 \mathrm{mmol} / \mathrm{L}$, or $\mathrm{HbA} 1 \mathrm{c}$ level of $\geq 6.5 \%$ were considered as having diabetes.

\section{Reducing bias}

To reduce selection bias, we included all laboratory-confirmed cases and a random sample of laboratory-confirmed controls from the orthopedic clinic of KAUH. To reduce confounding, we excluded, from both groups, those patients with type $1 \mathrm{DM}$, congenital hypothyroidism, autoimmune and Hashimoto's thyroiditis, previous thyroid surgery or irradiation, radioactive iodine therapy, iron infiltration due to hemochromatosis, certain medications (thalidomide, stavudine, amiodarone, lithium carbonate), specific chemotherapy (aminoglutethimide), subacute thyroiditis, lymphocytic thyroiditis, central hypothyroidism due to pituitary adenoma or surgery, and hypothalamic disorder affecting thyroid function. ${ }^{15,16}$ To reduce information bias, we used the results of laboratory tests to validate our primary outcome (hypothyroidism) and primary exposure (DM-II).

\section{Sample size}

We planned a study of independent cases and controls with one control per case. We assumed that the probability of exposure among controls is 0.2 . If the true probability of exposure among cases is 0.4 , we needed to study 81 cases and 81 controls to be able to reject the null hypothesis that the exposure rates for cases and controls are equal with probability (power) of 0.8 . The type I error probability associated with this test of the null hypothesis is 0.05 . We used an uncorrected chisquared statistic to evaluate this null hypothesis. We decided to increase the sample by $33 \%$ to account for incomplete data; thus, 121 patients were included in each group.

\section{Statistical methods}

To describe our data, we used frequencies and absolute numbers for categorical variables and mean and SD for continuous data. Differences between cases and controls in categorical variables were assessed by the chi-squared test or Fisher's exact test, when the data were sparse. Differences between cases and controls in continuous variables were evaluated 
by Student's $t$-test for independent samples. A $P$-value of $<0.05$ was considered significant. We used univariate logistic regression to identify factors associated with hypothyroidism. We constructed multivariate logistic regression models to adjust for potential confounders for the association between hypothyroidism and DM-II. The dependent variable was hypothyroidism, and the independent variables were age, sex, DM-II, HbA1c, insulin, oral hypoglycemic agents, diabetic foot, retinopathy, nephropathy, hypertension, CAD, and stroke. We used the backward elimination procedure to select the covariates for the multivariate regression model. We used SPSS version 21.0 for all statistical analyses.

\section{Ethical considerations}

This study was approved by the Biomedical Research Ethics Unit at King Abdulaziz University. We removed all patientidentifying variables before analysis to assure anonymization of data. We limited access to the data to the study team and stored the data in a computer secured with a password. Patient informed consent to review their medical files was waived due to the anonymization of data. Our study was conducted in accordance with the principles of the Declaration of Helsinki.

\section{Results}

We included 121 cases with hypothyroidism and 121 controls without hypothyroidism. Table 1 shows the differences between cases and controls. In comparison to controls, cases were significantly older $(P=0.005)$, suffered more often from DM-II $(P<0.001)$, had significantly higher HbA1c levels $(P=0.03)$, used insulin $(P<0.001)$ and oral hypoglycemic agents $(P<0.001)$ more often, and suffered more often from nephropathy $(P<0.001)$, hypertension $(P<0.001)$, CAD $(P<0.001)$, and stroke $(P=0.04)$. We found no significant difference between cases and controls based on sex, diabetic foot, and retinopathy (Table 1).

Using univariate regression, the risk of hypothyroidism was significantly associated with DM-II $(\mathrm{OR}=6.7 ; 95 \% \mathrm{CI}$ : 3.70-12.10; $P<0.001)$, CAD (OR=37.7; 95\% CI: 5.04-282; $P<0.001)$, and older age $(\mathrm{OR}=1.02 ; 95 \% \mathrm{CI}: 1.01-1.04$; $P=0.006$ ) (Table 2).

Using multivariate regression, the risk of hypothyroidism was significantly associated with DM-II (OR=4.14; 95\% CI: $2.2-7.8 ; P<0.001)$ and CAD (OR=14.15; 95\% CI: $1.80-111.43 ; P=0.012$ ) (Table 3 ).

\section{Discussion}

Our study found a strong positive association between hypothyroidism and DM-II, with an OR $>4$. We found that DM-II was significantly more common among cases
Table I General characteristics of cases and controls $(n=242)$

\begin{tabular}{|c|c|c|c|}
\hline Parameter & Cases & Controls & $P$-value \\
\hline $\begin{array}{l}\text { Age } \\
\text { Mean (SD) } \\
\text { Median (IQR) }\end{array}$ & $\begin{array}{l}55.71(16.46) \\
58(23.25)\end{array}$ & $\begin{array}{l}50.20(14.09) \\
50(22)\end{array}$ & 0.005 \\
\hline $\begin{array}{l}\text { Sex, N (\%) } \\
\text { Male } \\
\text { Female }\end{array}$ & $\begin{array}{l}21(47.7) \\
101(50.5)\end{array}$ & $\begin{array}{l}23(52.3) \\
99(49.5)\end{array}$ & 0.74 \\
\hline $\begin{array}{l}\text { DM-II, N (\%) } \\
\text { Yes } \\
\text { No }\end{array}$ & $\begin{array}{l}\text { 7I (77.2) } \\
5 \mathrm{I}(33.6)\end{array}$ & $\begin{array}{l}21(22.8) \\
101(66.4)\end{array}$ & $<0.001$ \\
\hline $\begin{array}{l}\text { HbAlc } \\
\text { Mean (SD) } \\
\text { Median (IQR) }\end{array}$ & $\begin{array}{l}4.33(4.37) \\
5.48(7.50) \\
\end{array}$ & $\begin{array}{l}3.2 I(3.4 I) \\
2.25(5.84)\end{array}$ & 0.03 \\
\hline $\begin{array}{l}\text { Insulin, N (\%) } \\
\text { Yes } \\
\text { No }\end{array}$ & $\begin{array}{l}16(100.0) \\
106(46.5)\end{array}$ & $\begin{array}{l}0(0) \\
122(53.5)\end{array}$ & $<0.001$ \\
\hline $\begin{array}{l}\text { Oral hypoglycemic } \\
\text { drugs, N (\%) } \\
\text { Yes } \\
\text { No }\end{array}$ & $\begin{array}{l}26(76.5) \\
96(45.7)\end{array}$ & $\begin{array}{l}8(23.5) \\
114(54.3)\end{array}$ & $<0.001$ \\
\hline $\begin{array}{l}\text { Diabetic foot, N (\%) } \\
\text { Yes } \\
\text { No }\end{array}$ & $\begin{array}{l}3(100.0) \\
119(49.4)\end{array}$ & $\begin{array}{l}0(0) \\
122(50.6)\end{array}$ & 0.08 \\
\hline $\begin{array}{l}\text { Retinopathy, N (\%) } \\
\text { Yes } \\
\text { No }\end{array}$ & $\begin{array}{l}I(100.0) \\
|2|(49.8)\end{array}$ & $\begin{array}{l}0(0) \\
122(50.2)\end{array}$ & 0.32 \\
\hline $\begin{array}{l}\text { Nephropathy, N (\%) } \\
\text { Yes } \\
\text { No }\end{array}$ & $\begin{array}{l}10(100.0) \\
112(47.9)\end{array}$ & $\begin{array}{l}0(0) \\
122(52.1)\end{array}$ & $<0.001$ \\
\hline $\begin{array}{l}\text { HTN, N (\%) } \\
\text { Yes } \\
\text { No }\end{array}$ & $\begin{array}{l}51(100.0) \\
71(36.8)\end{array}$ & $\begin{array}{l}0(0.0) \\
122(63.2)\end{array}$ & $<0.001$ \\
\hline $\begin{array}{l}\text { CAD, N (\%) } \\
\text { Yes } \\
\text { No }\end{array}$ & $\begin{array}{l}29(96.7) \\
93(43.5)\end{array}$ & $\begin{array}{l}\text { I (3.3) } \\
\text { I2I (56.5) }\end{array}$ & $<0.001$ \\
\hline $\begin{array}{l}\text { Stroke, N (\%) } \\
\text { Yes } \\
\text { No }\end{array}$ & $\begin{array}{l}4(100.0) \\
118(49.2)\end{array}$ & $\begin{array}{l}0(0) \\
122(50.8)\end{array}$ & 0.04 \\
\hline
\end{tabular}

Abbreviations: CAD, coronary artery disease; DM-II, type 2 diabetes mellitus; HTN, hypertension; IQR, interquartile range.

Table 2 Univariate logistic regression and OR results

\begin{tabular}{|c|c|c|}
\hline Parameter & OR $(95 \% \mathrm{Cl})$ & $P$-value \\
\hline Age & $1.02(1.01-1.04)$ & 0.006 \\
\hline Sex & $1.12(0.58-2.15)$ & 0.74 \\
\hline DM-II & $6.70(3.70-12.10)$ & $<0.001$ \\
\hline $\mathrm{HbAlc}$ & $1.08(1.01-1.15)$ & 0.029 \\
\hline Insulin & $1.86(-)^{\mathrm{a}}$ & 0.99 \\
\hline $\begin{array}{l}\text { Oral hypoglycemic } \\
\text { drugs }\end{array}$ & $3.86(1.67-8.92)$ & 0.002 \\
\hline HTN & $2.78(-)^{a}$ & 0.99 \\
\hline CAD & $37.73(5.05-282.08)$ & $<0.001$ \\
\hline Stroke & $1.67(-)^{\mathrm{a}}$ & 0.99 \\
\hline Diabetic foot & $1.66(-)^{\mathrm{a}}$ & 0.99 \\
\hline Retinopathy & $1.63(-)^{\mathrm{a}}$ & 1.00 \\
\hline Nephropathy & $1.76(-)^{\mathrm{a}}$ & 0.99 \\
\hline
\end{tabular}

Note: ${ }^{a} \mathrm{Cl}$ could not be estimated due to sparse data, as at least one cell included less than five patients.

Abbreviations: CAD, coronary artery disease; DM-II, type 2 diabetes mellitus; HTN, hypertension. 
Table 3 Multivariate logistic regression and OR results

\begin{tabular}{|l|l|l|}
\hline Parameter & OR (95\% Cl) & $P$-value \\
\hline DM-II & $4.14(2.20-7.80)$ & $<0.001$ \\
\hline CAD & $14.15(1.80-111.43)$ & 0.012 \\
\hline
\end{tabular}

Abbreviations: CAD, coronary artery disease; DM-II, type 2 diabetes mellitus.

(77.2\%) than among controls (22.8\%). The high prevalence of DM-II in Saudi Arabia, ${ }^{3}$ with approximately 3.4 million affected adults, could represent a high risk for developing hypothyroidism among the population. Hypothyroidism is a known risk factor for CAD and is associated with increased all-cause mortality independent of CAD risk factors. ${ }^{20,21}$ DM-II patients are also at a high risk of developing CAD and usually have more significant adverse prognosis following CAD than patients without DM-II. ${ }^{22}$ As shown in the "Results" section, 31 of the diabetic patients in the cases group had CAD compared to only one diabetic patient in the control group. This difference was also statistically significant with a $P$-value of $<0.001$. This could be due to the presence of these two major risk factors for such complications in the cases group, which increased the risk even more when compared to the presence of DM-II alone in the control group. In addition, there were elevated $\mathrm{HbA} 1 \mathrm{c}$ levels in the cases group with a mean of $8.5( \pm 2.6)$ and a median of 8 (2.6) when compared to the controls with a mean and median of $8.0( \pm 1.7)$ and $7.4(1.7)$, respectively. This could be an indicator of developing such complications in diabetic patients. Other complications including nephropathy, stroke, diabetic foot, and retinopathy were found in approximately $25 \%$ of the cases with DM. On the other hand, none of the diabetic patients in the control group had any of these complications. This could imply that the coexistence of both hypothyroidism and DM-II could alter patients' health conditions and metabolic control, and might also increase their mortality. This could also decrease the quality of life for those patients if not detected early.

Several studies found a positive association between DM-II and hypothyroidism. However, the strength of the association varied between the studies. Research conducted on 221 cases with DM-II in eastern Nepal found that the prevalence of clinical and subclinical hypothyroidism in patients with diabetes was $4.05 \% .{ }^{17}$ Another study on 202 DM-II patients in India showed that the prevalence of thyroid dysfunctions among diabetic patients was $31 \%$, ranging between $16.3 \%$ subclinical hypothyroidism, $11.4 \%$ hypothyroidism, $2 \%$ subclinical hyperthyroidism, and 1.5\% hyperthyroidism. ${ }^{13}$ Another study showed a prevalence of primary hypothyroidism of $11.8 \%$ in DM-II subjects. ${ }^{18}$
Recent literature has shown an increased risk of subclinical hypothyroidism among patients with DM-II. In a systematic review and meta-analysis, DM-II patients were more likely to have subclinical hypothyroidism than the healthy population and subclinical hypothyroidism was associated with increased diabetic complications. ${ }^{19}$ Similarly, in our study, hypothyroidism was more prevalent among patients with diabetes.

Hypothyroidism is a known risk factor for CAD and is associated with increased all-cause mortality independent of CAD risk factors. ${ }^{20,21}$ On the other side, DM-II patients are at a greater risk of developing CAD and usually have a more adverse prognosis following CAD. ${ }^{22}$ As shown in our results, patients with $\mathrm{CAD}$ were at increased risk of hypothyroidism, irrespective of whether or not they were diabetic. This implies that the coexistence of hypothyroidism and DM-II could increase the risk of CAD. In several studies hypothyroidism has been considered as a cardiovascular risk factor, mainly because of its association with elevated serum total cholesterol and low-density lipoprotein levels. Hypercholesterolemia in hypothyroidism probably results from reduced catabolism of lipoproteins, a phenomenon that may be explained by a decreased expression of lipoprotein receptors. ${ }^{23,24}$ In our study we found a strong ( $\left.\mathrm{OR}=14.15\right)$ and highly significant $(P=0.012)$ association between hypothyroidism and coronary heart disease. However, as our case-control study was retrospective, the temporal relationship between hypothyroidism and coronary heart disease remains unclear and the risk of reverse causation could not be excluded.

Our study had several strengths. We reduced the risk of selection bias by including all laboratory-confirmed cases and a random sample of laboratory-confirmed controls. We refrained from including clinically diagnosed study participants to reduce the risk of misclassification errors. However, our study also had several limitations. Our sample size was limited and the distribution of the data for several variables was skewed; none of the patients in the control group had diabetic foot, retinopathy, nephropathy, stroke, or hypertension. Because of this limitation, we were unable to estimate the CI for these variables. Moreover, we used electronic and paper-based hospital records as data source. Therefore, we were unable to adjust for further potential confounders, like dietary iodine and family history of hypothyroidism, for which no data were documented in the hospital records.

\section{Conclusions and recommendations}

Our study found that patients with DM-II were at increased risk of developing hypothyroidism. Adequate management 
and control of DM-II might reduce the risk of developing hypothyroidism. Further research using a prospective cohort study design and a larger sample size from multiple study centers is needed to confirm these findings.

\section{Acknowledgment}

We would like to thank Editage (www.editage.com) for English language editing.

\section{Disclosure}

The authors report no conflicts of interest in this work.

\section{References}

1. Shaw JE, Sicree RA, Zimmet PZ. Global estimates of the prevalence of diabetes for 2010 and 2030. Diabetes Res Clin Pract. 2010;87(1):4-14.

2. Hammouda SA, Sultan EA, Mohamadin AM. Endocrinology \& Metabolic Syndrome. OMICS. 2017;6:2.

3. Alqurashi KA, Aljabri KS, Bokhari SA. Prevalence of diabetes mellitus in a Saudi community. Ann Saudi Med. 2011;31(1):19-23.

4. Klein R, Klein BE, Moss SE. Visual impairment in diabetes. Ophthalmology. 1984;91(1):1-9.

5. Perneger TV, Brancati FL, Whelton PK, Klag MJ. End-stage renal disease attributable to diabetes mellitus. Ann Intern Med. 1994;121(12):912-918.

6. Haffner SM, Lehto S, Rönnemaa T, Pyörälä K, Laakso M. Mortality from coronary heart disease in subjects with type 2 diabetes and in nondiabetic subjects with and without prior myocardial infarction. $N$ Engl J Med. 1998;339(4):229-234.

7. Liu W, Yang J, Yu M, Pan S. Screening for subclinical hypothyroidism in type 2 diabetes mellitus patients in Beijing (Article in Chinese). Clinical Focus. 2007;22(21):1558-1560.

8. Zhang N, Tang W, Lu W. Study on type 2 diabetes mellitus with subclinical hypothyroidism in Jiangsu. Zhongguo Shiyong Neike Zazhi/Chin J Pract Intern Med. 2009;29(12):1106-1108.

9. Ghazali SM, Abbiyesuku FM. Thyroid dysfunction in type 2 diabetics seen at the University College Hospital, Ibadan, Nigeria. Niger J Physiol Sci. 2010;25(2):173-179.

10. Hage M, Zantout MS, Azar ST. Thyroid Disorders and Diabetes Mellitus. J Thyroid Res. 2011;2011(6179):1-7.
11. Díez JJ, Sánchez P, Iglesias P. Prevalence of thyroid dysfunction in patients with type 2 diabetes. Exp Clin Endocrinol Diabetes. 2011;119(4): 201-207.

12. Radaideh AR, Nusier MK, Amari FL, et al. Thyroid dysfunction in patients with type 2 diabetes mellitus in Jordan. Saudi Med J. 2004;25(8):1046-1050.

13. Demitrost L, Ranabir S. Thyroid dysfunction in type 2 diabetes mellitus: $A$ retrospective study. Indian J Endocrinol Metab. 2012;16(Suppl 2):S334

14. Ministry of Health. Guidelines for diabetes, 1st ed. Riyadh, Saudi Arabia: El-Khalid Offset Printing Press; 2013.

15. Kadiyala R, Peter R, Okosieme OE. Thyroid dysfunction in patients with diabetes: clinical implications and screening strategies. Int J Clin Pract. 2010;64(8):1130-1139.

16. Roberts CG, Ladenson PW. Hypothyroidism. Lancet. 2004;363(9411): 793-803.

17. Maskey R, Shakya DR, Baranwal JK, Lavaju P, Karki P, Poudel SK. Hypothyroidism in diabetes mellitus patients in Eastern Nepal. Indian J Endocrinol Metab. 2015;19(3):411.

18. Distiller LA, Polakow ES, Joffe BI. Type 2 diabetes mellitus and hypothyroidism: the possible influence of metformin therapy. Diabet Med. 2014;31(2):172-175.

19. Díez JJ, Iglesias P. An analysis of the relative risk for hypothyroidism in patients with Type 2 diabetes. Diabet Med. 2012;29(12): $1510-1514$.

20. Vanhaelst L, Neve P, Chailly P, Bastenie PA. Coronary-artery disease in hypothyroidism. Observations in clinical myxoedema. Lancet. 1967;2(7520):800-802.

21. Becker C. Hypothyroidism and atherosclerotic heart disease: pathogenesis, medical management, and the role of coronary artery bypass surgery. Endocr Rev. 1985;6(3):432-440.

22. Mcquade C, Skugor M, Brennan DM, Hoar B, Stevenson C, Hoogwerf BJ. Hypothyroidism and moderate subclinical hypothyroidism are associated with increased all-cause mortality independent of coronary heart disease risk factors: a PreCIS database study. Thyroid. 2011;21(8):837-843.

23. Thompson GR, Soutar AK, Spengel FA, Jadhav A, Gavigan SJ, Myant NB. Defects of receptor-mediated low density lipoprotein catabolism in homozygous familial hypercholesterolemia and hypothyroidism in vivo. Proc Natl Acad Sci U SA. 1981;78(4):2591-2595.

24. Scarabottolo L, Trezzi E, Roma P, Catapano AL. Experimental hypothyroidism modulates the expression of the low density lipoprotein receptor by the liver. Atherosclerosis. 1986;59(3):329-333.

25. Von Elm E, Altman DG, Egger M, Pocock SJ, Gøtzsche PC, Vandenbroucke JP, Strobe Initiative. The Strengthening the Reporting of Observational Studies in Epidemiology (STROBE) statement: guidelines for reporting observational studies. PLoS medicine. 2007;4(10):e296.
International Journal of General Medicine

\section{Publish your work in this journal}

The International Journal of General Medicine is an international peer-reviewed open-access journal that focuses on general and internal medicine, pathogenesis, epidemiology, diagnosis, monitoring and treatment protocols. The journal is characterized by the rapid reporting of reviews, original research and clinical studies across all disease areas.

\section{Dovepress}

The manuscript management system is completely online and includes a very quick and fair peer-review system, which is all easy to use. Visit http://www.dovepress.com/testimonials.php to read real quotes from published authors. 